\title{
Nuevas fórmulas de periodismo: Periodismo de proximidad 2.0
}

\author{
David CALDEVILLA* \\ caldevilla@ucm.es
}

(Abstracts y palabras clave al final del artículo)

Propuesto: 2 de abril de 2013

Evaluado: 10 de abril de 2013

Aceptado: 15 de abril de 2013

\section{INTRODUCCION: DE LOS MEDIOS DE COMUNICACIÓN 1.0 AL 2.0.}

El periodismo ha evolucionado vertiginosamente en el epílogo del siglo pasado y en los prolegómenos del que recién hemos comenzado. El acceso casi instantáneo a la información, la proliferación de fuentes, la rapidez de comunicación y la externalización del uso de Internet fuera del ámbito meramente académico o profesional, propio del entorno laboral, ha abierto nuevas ventanas para esta 'vieja' profesión que poco a poco van siendo asimiladas por periodistas y lectores.

La prensa tradicional, ejerciente de fiel reflejo de la sociedad que representa a diario en sus cabeceras, ha tenido que ir adaptándose a las nuevas demandas cibernéticas para dar acogida a sus nuevos lectores a través de las actuales tecnologías y sus amplias posibilidades. Una de las ventajas, derivadas de lo anterior, es que "las redes de comunicación en línea, desarrolladas como parte de ese proceso global, comprenden varias funciones que influyen en el mundo que nos rodea. Asi, [...] la amalgama de nuevas culturas sociales; el aprovechamiento y la conciliación a nuevos contextos y la velocidad con que se transfieren recursos e intercambios que hacen del mundo una sola cosa, es decir, una sola Aldea", lo cual contrasta con este periodismo próximo, quien a su vez, merced a lo binario, se convierte en globalizado. (Caldevilla, 2008: 121).

Es así como a partir de los años 90 los principales diarios de nuestro país abrieron sus ediciones en línea, lo hoy llamado 1.0 (es decir, el volcado de la edición impresa a Internet, con la misma información y sólo para su lectura), de forma bastante primitiva y normalmente bajo fórmula de pago y no fue hasta el año 2000 cuando se dio el salto al modelo 2.0, potenciando de este modo la participación, creando contenidos exclusivos en muchos casos gratuitos, fomentando las Redes sociales,

\footnotetext{
* Profesor Contratado Doctor UCM
} 
animando a la opinión y los foros de debate, adjuntando contenidos audiovisuales prolijamente (con canal de televisión en línea propio, como es el caso de El Mundo TV) de tal forma y fuerza que ahora es difícil encontrar un periódico de papel que no tenga versión en la Red de Redes.

Nos hallamos, por tanto, ante una prensa digital relativamente joven que va evolucionando poco a poco, imitando a los periódicos gratuitos que aparecieron en España a mediados de los $90 \mathrm{y}$ apostando fuertemente por la publicidad como nueva forma de ingreso, por encima del derivado históricamente del precio de cada ejemplar, liberando así la información sin perder lucro. Como reza el manifiesto 2.0, éste es un mundo basado en una información abierta y libre.

Esta situación bisoña, contrasta con la aparente madurez de sus autores, quienes plantean unos postulados formales -autoriales- reconocibles, herederos éstos de la tradición periodística en España, y por ende, mundial. Cabe entroncar por ello este tipo de periodismo con el que, como nos recuerda Aladro Vico se puede hallar desde los 90 ya que "con las extensiones tecnológicas del ordenador y el teléfono móvil, la barrera de la intimidad se desdibuja, igualmente se borra la identidad como pilar de la racionalidad tal y como existe en el mundo predigital, y la vida privada y los derechos de identidad o de autoría evolucionan hacia un contexto en el que parecen adquirir un valor social diferente. Aparece, pues, una convergencia de estas esferas que hace que se fundan, mediante los contextos interpersonales tecnológicos, los procesos intra e interactivos y masivos, en modos que aún están en proceso de definición. Este cambio nos hace recordar la capacidad de la comunicación humana para flexibilizar sus dimensiones de acción: la ineficacia de conceptos como identidad, autoría, emisor activo, receptor pasivo, ante fenómenos como la actual convergencia digital y el surgimiento de la web 2.0." (Aladro Vico, 2011: 85)

Esta tendencia al anonimato, a lo bidireccional simétrico, a lo 2.0, a la cercanía a la fuente y a la difusión masiva configura un puzzle que forma un imagen de la comunicación actual.

Vaquerizo (2012: 118), sistematiza el aspecto tecnológico de la Web 2.0 ya que "permite disponer de un conjunto de herramientas sofisticadas de publicación y gestión de contenidos. En el aspecto social, posibilita la aparición de una inteligencia colectiva a partir de la agregación de aportaciones individuales no sistematizadas ni guiadas explícitamente" y recoge en una tabla esquemática algunas de las más destacadas aplicaciones útiles que recogemos aquí. 
Tabla 1. Aplicaciones de la Web 2.0.

\section{Algunas aplicaciones de las herramientas Web 2.0}

\begin{tabular}{|c|c|c|}
\hline $\begin{array}{l}\text { - } \text { Bitácoras }(\text { Blog) } \\
\text { - } \text { Enciclopedias (Wiki) } \\
\text { - } \text { Foros } \\
\text { - } \text { Twitter } \\
\text { - Calendario en línea } \\
\text { - } \text { - Podreo electrónico } \\
\text { - } \text { audio) } \\
\text { - Eortafolio electrónico } \\
\text { - línea } \\
\text { - Videocon de imagen en } \\
\text { - Cuestionarios en línea } \\
\text { - Autoevaluación en } \\
\text { línea }\end{array}$ & $\begin{array}{l}\text { - Streaming (imágenes } \\
\text { en directo) } \\
\text { - Edición de vídeo en } \\
\text { línea (Youtube...) } \\
\text { - Edición de audio } \\
\text { (audacity, garage- } \\
\text { band, etc.) } \\
\text { - Repositorio y compar- } \\
\text { tición de imágenes } \\
\text { - Red social } \\
\text { (Facebook...) } \\
\text { - Ofimática en línea } \\
\text { (procesador de texto, } \\
\text { hoja de cálculo...) }\end{array}$ & $\begin{array}{l}\text { - Páginas personaliza- } \\
\text { das } \\
\text { - Mundos virtuales } \\
\text { - Marcadores sociales } \\
\text { - Búsqueda mediante } \\
\text { etiquetas } \\
\text { - Gestión bibliográfica } \\
\text { - Bibliotecas digitales } \\
\text { colaborativas } \\
\text { - Lectores de feeds } \\
\text { (agregadores de infor- } \\
\text { mación) } \\
\text { - Otras... }\end{array}$ \\
\hline
\end{tabular}

\section{EL PERIODISMO DE PROXIMIDAD, LOS MEDIOS LOCALES.}

Paradójicamente hemos comprobado cómo lo global ayuda a desarrollar lo local. Para hablar del periodismo local, es necesario que pongamos unos límites al término 'local' al que nos estamos refiriendo ya que la Red, por su carácter global no conoce fronteras geográficas. Alicia Martínez Juan, en su artículo sobre los retos del periodista local en la Red, define las características del periodismo local en los medios convencionales (Martínez Juan, 2003):

- La localización del medio en un lugar físico y delimitado tanto geográfica como jurídicamente y cuyos habitantes reúnan una unicidad cultural y tradicional propias y unos intereses comunes.

- Audiencia local caracterizada por la cercanía entre el ciudadano y las instituciones de gobierno;

- Contenidos elaborados a partir de la sucesos sociales, económicos, eventos deportivos, culturales y políticos, de ese espacio limitado;

- Intereses (políticos, económicos y sociales) del medio en el espacio en que se expresa;

- Responsabilidad social del medio con el espacio en el que se encuentra que le obliga a participar o influir activamente en las relaciones.

Este periodismo local en medios convencionales presenta su traslado binario variando notablemente sus características en lo que a audiencia se refiere. Si bien, el 
periodismo local de papel es distribuido en barrios, en ciudades, ya en Internet la audiencia se magnifica, pudiendo ser accesible desde cualquier punto del mundo.

Por lo tanto, las características del Periodismo Local en línea podríamos definirlas, conviniendo de nuevo con Alicia Martínez Juan (2003), siguiendo las siguientes reflexiones:

- Debido a que Internet derriba en muchos casos las fronteras espaciales, dada su capacidad de interconexión entre los ciudadanos y la Administración, el concepto de "local" se ve ampliado hasta el ámbito regional. Podemos por tanto calificar de periodismo local en línea a "aquel trata las diferentes temáticas periodísticas desde el punto de vista de la proximidad al ciudadano, sea cual sea la procedencia de la información".

- Con las nuevas tecnologías no existe la necesidad, aunque sea recomendable, de que la redacción se encuentre ubicada físicamente en el ámbito local sino que cada vez más, podemos encontrar la redacción de un periódico local en otro sitio, siendo las agencias o los propios periodistas los que se desplacen al lugar de los acontecimientos.

Pero, lo más importante es que con Internet, la distribución del periódico local rompe la barrera fronteriza del espacio físico para expandirse y ser accesible desde cualquier lugar del mundo. Finado es el tiempo de no ser noticia por no ser accesible.

No todo es un camino de rosas económico. Algunos autores ya han reparado en estas carencias derivadas de que nos "...encontramos un amplio abanico de medios locales, algunos de ellos con fuerte implantación en sus respectivos territorios, pero que, marcados por una estructura poco profesionalizada y un mercado publicitario de reducidas dimensiones, mantienen una ardua batalla por la supervivencia" (Masip, 2008: 36), lo cual nos lleva a la consideración de que si los medios tecnológicos son baratos, la falta de profesionalidad es lo que lleva a la carencia de recursos. No es momento aquí de hablar del fin de la profesión periodística, y lugar habrá en un futuro para ello, pero las bases para este óbito se asientan primero sobre este dato económico y, segundo, sobre la gran accesibilidad a la tecnología por parte del público lego en periodismo que se erige como fuente cercana a los hechos.

\subsection{HISTORIA DEL PERIODISMO LOCAL EN LÍNEA}

El año 1994 marcó el inicio de las publicaciones digitales en España. Fue este año cuando una revista valenciana, El Temps, inauguró su versión electrónica, tomando la delantera a más de un centenar de periódicos publicados en todo el territorio español. Poco tiempo después, el Boletín Oficial del Estado se introduce en la Red, ofreciendo íntegros sus contenidos bajo la modalidad de suscripción; y en el mes de noviembre del mismo año, El Periódico de Catalunya inaugura su portal, convirtiéndose así en el primer periódico español con versión digital de libre acceso.

Un año más tarde, 1995, la prensa en catalán aparece también en la Red, con Avui. Al mismo tiempo La Vanguardia, de Barcelona, estrena su edición digital, y poco después lo hizo el Diario Vasco de San Sebastián, con una versión semanal que 
en noviembre se convirtió en una publicación diaria. Más tarde aparecieron $L a$ Gaceta de los Negocios digital y ABC-e, perteneciente al grupo Vocento.

No fue hasta marzo de 1996, con la aparición de Hispanidad, cuando podemos hablar de la primera publicación puramente en línea sin referente en papel. A la vez arrancó El Mundo.es, que se ha convertido actualmente en el periódico digital español con mayor número de visitas. Ese mismo año, y coincidiendo con su vigésimo aniversario, El País puso en marcha una edición electrónica que pronto fue la preferida de los internautas pero con la salvedad de que tenía partes de libre acceso y partes bajo fórmula de suscripción por pago.

También en 1996 crearon su versión digital los diarios Mundo Deportivo y Expansión. Este último, propiedad del grupo Recoletos, fue el adelantado en la venta de productos en línea, ya que desde 1997 comercializó gráficas de bolsa (el archifamoso chartismo).

En marzo de 1998 comienza su experiencia digital Cinco Días (grupo Prisa), y poco tiempo después, El Día del Mundo, primera edición regional de un diario disponible en la Red. También arranca ese año la difusión electrónica de los suplementos. En 1999, El País Digital sigue la misma senda e incluye entre su oferta Ciberp@ís.

Dos años después, año 2000, son ya 81 los periódicos con doble edición (digital y en papel) y en junio de 2005, superaron el centenar.

Como es lógico, las estrategias de las distintas cabeceras han ido evolucionando a lo largo de esta última década, marcadas por los constantes cambios de mercado. Las ediciones inicialmente se espaciaban entre ellas con frecuencia de 12 y hasta 24 horas, aunque hoy en día son ya ediciones continuas, también llamadas, 'en tiempo real'.

En los primeros años de existencia de los periódicos en línea, la dotación de personal para estas secciones era muy limitada, y en la mayoría de los casos se componía únicamente de algún redactor que se dedicaba a volcar, sin más, en la Red los contenidos de la edición del día. A medida que fue creciendo el peso de las versiones electrónicas, surgió la necesidad de actualizar sus contenidos con regularidad para favorecerse de la omnipresencia e inmediatez de la Red y ofrecer al público actualizaciones constantes, aumentando considerablemente las plantillas de redactores dedicadas a las versiones en línea de los periódicos (Salaverría, 2004).

En cuanto al diseño, se observa que durante la década de los noventa abundaban las composiciones rudimentarias, pero que pronto fueron mejorando a medida crecía la audiencia. Inicialmente las versiones en línea eran simples calcos de los diarios de papel, con una explotación mínima de las posibilidades que ofrecían las nuevas tecnologías multimedia -quienes también fueron ampliándose, es cierto, permitiendo nuevos lenguajes periodísticos-. Hoy en día las editoras cuidan cada vez más el diseño de sus productos electrónicos, introduciendo nuevos elementos adicionales a la palabra, como pueden ser vídeos e imágenes (algunas cabeceras, como Marca o El Mundo, mostraron siempre especial interés por esta vertiente del trabajo digital), hasta alcanzar la riqueza y variedad actual (Edo, 2002).

Las empresas también se han lanzado a aventuras electrónicas que van más allá de la publicación de diarios. Un buen ejemplo de ello es el periódico Marca que en 1999 presentó una versión personalizada del periódico por la que el lector accedía sólo a las noticias vinculadas a su ciudad, deporte o club favorito, con clara intención local. 


\section{VENTAJAS E INCONVENIENTES LOGÍSTICOS DEL SALTO A LA RED DE LOS MEDIOS LOCALES.}

Colin Sparks (2002), prestigioso investigador sobre la convergencia digital de los medios audiovisuales, opina que la superación de las fronteras de la Red, elimina las ventajas competitivas de los medios de comunicación local ya que entraría en competencia directa con medios mucho más potentes a nivel nacional o incluso mundial ya que el espacio de publicación y accesibilidad es compartido.

Sin embargo Sparks defiende que los medios locales en línea, lejos de reducir su ventaja frente a otros medios más grandes, la aumentan ya que al romper las barreras de distribución geográfica, amplían igualmente su audiencia potencial. Por ello, aquellos ciudadanos 'locales' que, por avatares del destino, se encuentren fuera de su lugar de origen, pueden acceder desde su propio ordenador personal al medio de su localidad con la posibilidad de comunicarse con sus familiares cercanos o simplemente enterarse de los acontecimientos que están ocurriendo y que pueden serle de gran interés. Incluso las bitácoras unidas a estas publicaciones ayudan a fomentar el flujo de audiencia.

No olvidemos que un diario local es, entre otras cosas, un reclamo publicitario turístico y se nutre de publicidad local principalmente, por lo tanto, la expansión de información a lugares donde la localidad no es conocida, atrae al turismo y a inversores.

\section{EL MERCADO DE LOS CIBER-MEDIOS EN LA ACTUALIDAD.}

Salaverría (2008) define acertadamente las características de los cíber-medios españoles durante estos últimos años con cinco características:

- Los diarios dominan la información en Internet: Los diarios, (locales, regionales, nacionales...) son la primera fuente de información periodística en la Red relegando a segundos y terceros puestos a las radios o las televisiones. La hegemonía de los diarios digitales se da tanto a escala nacional como autonómica.

- Los medios exclusivamente digitales buscan aún su consolidación en la Red: A pesar del lanzamiento de diversos proyectos editoriales exclusivamente para la Red (ADN.es en julio de 2007, Soity.es el 29 de diciembre de 2007, El Imparcial el 22 de enero de 2008, La Nación el 26 de febrero de 2008...). En España, como nos recuerda Salaverría, el primer ciberdiario de información generalista fue Hispanidad fundado en 1996. A partir de éste, con mayor o menor suerte, empezaron a proliferar una cantidad de diarios digitales como hemos comentado en el epígrafe anterior además de otros muchos "confidenciales" de tinte más amarillista o de opinión con una reputación cuanto menos cuestionable dada su parcialidad en muchos casos y el mercadeo de información. Sea como fuere, nos encontramos todavía ante un mercado joven y bastante inestable donde aparecen y desaparecen diarios continuamente. Sus problemas más importantes son las dificultades para conseguir la inversión por parte de los anunciantes (que siguen apostando todavía más por la prensa escrita) y el desconocimiento de gran parte de la audiencia de su existencia. 
- La información debe ser gratuita: Tras la crisis económica de Internet de comienzos de los años 2000, algunos medios digitales optaron por experimentar con modelos de negocio basados en el cobro por contenidos (Salaverría, 2008: 363-373).

Como hemos comentado, las inversiones publicitarias en línea están aún en mantillas. Según Infoadex, en 2008 los anunciantes invirtieron 260,3 millones de euros en Internet, un $12 \%$ más que el 2006. Sin embargo, aunque son buenos datos, la publicidad en la Red supone aún apenas el 2,2\% de la inversión total en medios convencionales.

\subsection{AUDIENCIAS DE LOS PRINCIPALES DIARIOS NACIONALES Y LOCA- LES EN SU VERSIÓN EN LÍNEA.}

La siguiente tabla, muestra las audiencias en octubre de 2009 según el observatorio del OJD (Oficina de Justificación de la Difusión) de los diarios más importantes a nivel nacional y local en España. Cabe destacar que no están todos los que son, pero sí son todos los que están, ya que OJD excluye ciertos medios como los dirigidos por Prisacom que sin duda encabezarían la escala debido al gran número de visitas a sus dos cabeceras más importantes en Internet: El País Digital y Diario Marca Digital que se encuentran según el medidor de audiencias Alexa en el cuarto y primer puesto respectivamente en el número de visitas a periódicos en nuestro país.

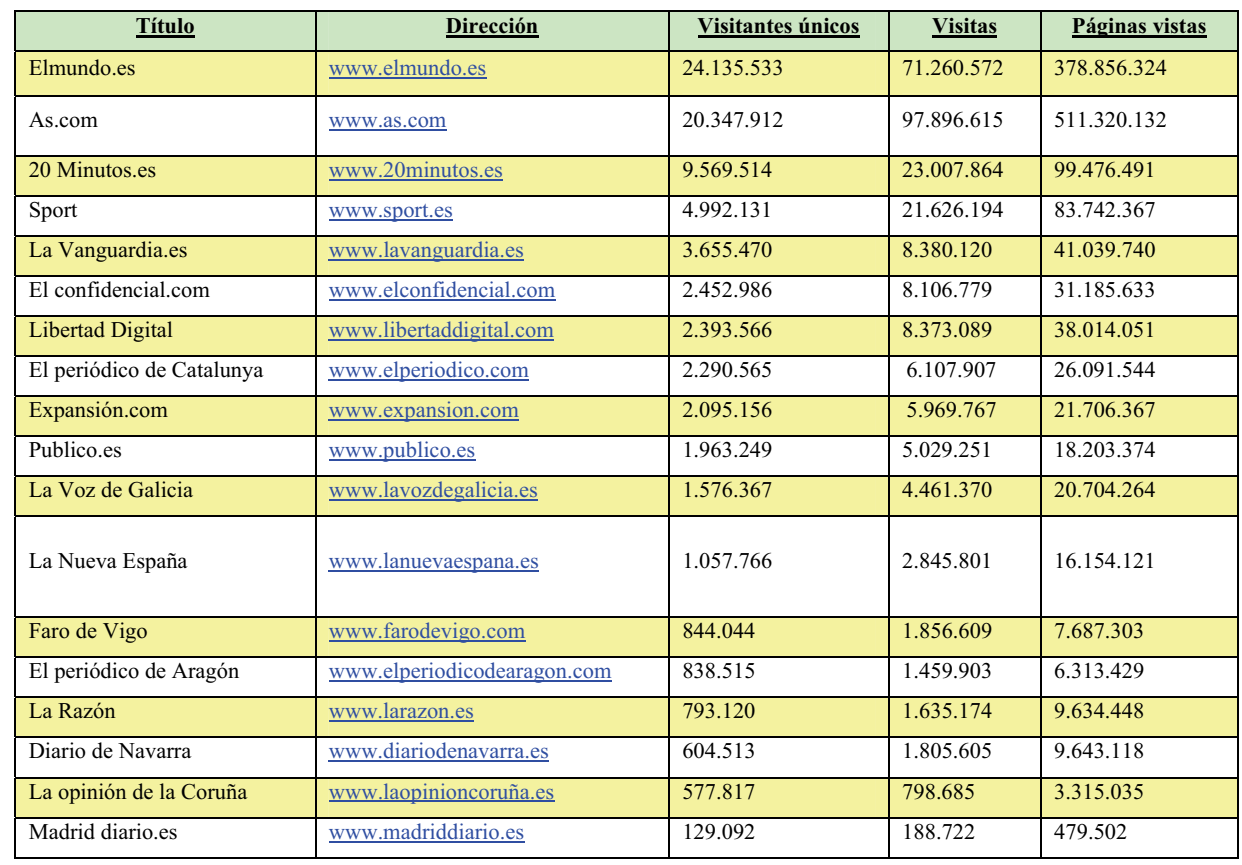

Fuente: OJD Interactiva, octubre 2009. (Nota: Los medios de Prisacom están autoexcluidos de estas mediciones) 
Cabe destacar de la tabla varias conclusiones al margen de que los medios del grupo Prisa (en especial El País) no aparezcan por decisión propia. La primera es que hay unas grandes diferencias entre la audiencia de los dos primeros diarios ( $E l$ Mundo y $A s$, ambos deportivos) y la del resto de diarios analizados por el OJD teniendo una clara hegemonía sobre sus competidores.

Podemos también observar que los medios regionales, se hacen un gran hueco entre los nacionales. Destaca el puesto que ocupa el diario Público (de tirada e información nacional, en aquel momento de papel y hoy sólo en línea) frente a otros diarios como El Periódico de Catalunya.

También podemos destacar los buenos resultados de otros periódicos más "modestos" como La Voz de Galicia, El Faro de Vigo o El Periódico de Aragón.

\section{ESTADO ACTUAL DEL PERIODISMO LOCAL EN LA RED EN LA COMUNIDAD DE MADRID}

La Comunidad de Madrid dispone de un gran número de publicaciones locales digitales registradas en la Dirección General de Medios de Comunicación de la Oficina de Comunicación del Gobierno: Diariocritico.com, Diario Directo, Estrella Digital, El Confidencial, El Confidencial Digital, El Plural, El Semanal Digital, Libertad Digital, Madridiario, Madridpress.com, Periodista Digital, Portal Local, PRNoticias, Extraconfidencial.com, El Digital de Madrid, Diario Abierto y La Quincena.

Para ejemplificar todo lo hablado hasta el momento, hemos escogido como muestra el periódico Madridiario (www.madridiario.es) con objeto de analizarlo para responder a las siguientes preguntas: ¿Se está realmente produciendo un replanteamiento en el periodismo local?, ¿Qué tipo de periodismo local se está haciendo actualmente en la Red? Para contestar a estas preguntas nos hemos fijado en los temas y su jerarquización, el tratamiento de la información y los recursos de interactividad.

Hemos circunscrito el análisis a un periódico exclusivamente en línea porque consideramos que los medios tradicionales que tienen presencia en Internet poseen ya una audiencia definida que simplemente cambia o amplía su forma de asomarse a los contenidos de ese medio. Además, su desarrollo virtual parte de unos contenidos ya elaborados por una redacción según una línea editorial y de negocio que ha demostrado ser exitosa en el mundo cotidiano.

Sin embargo, los medios de comunicación (escritos o audiovisuales) producidos exclusivamente para su difusión en la Red tienen una serie de características específicas para aprovechar las virtudes de lo 2.0 de manera directa, creando contenidos exclusivos y adaptados a la navegación por Internet. 


\subsection{MADRIDIARIO.ES.}

Madrid Diario nació en julio del año 2000 de la mano de su Director General José Brías y de Pedro Montoliú. Con más de 3.500 números se ha convertido en uno de los periódicos locales más longevos de la Comunidad y sigue manteniendo un número de visitantes diarios bastante elevado.

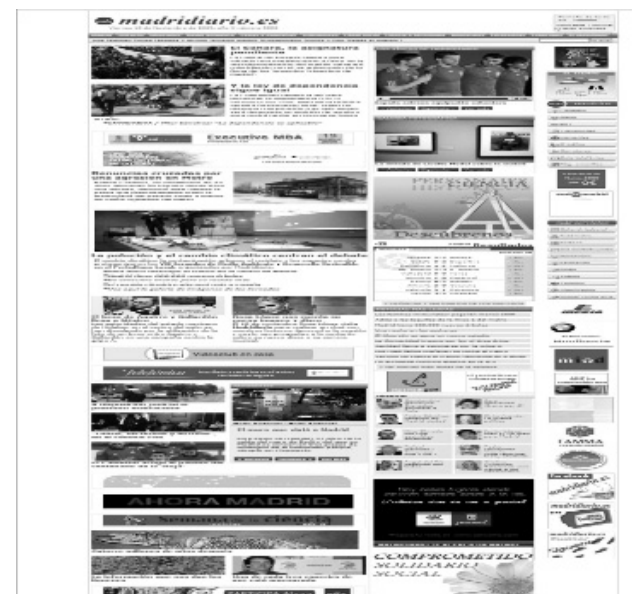

Captura de la portada de Madridiario.es

La página web de Madridiario cuenta con una serie de características análogas al resto de periódicos en línea locales. La primera se trata de una agrupación donde se aprecian las distintas noticias que se asocian por el ámbito de las mismas, pudiendo visualizar todas las de Madrid, concentrarlas por distrito y por municipio, etc. Otra de las características es la existencia de publicidad institucional de forma masiva mediante banderolas (banners) generalmente. También encontramos que hay ciertas secciones que destacan por su número de noticias; nos referimos a las que tratan, de algún modo, sobre el carácter social, el transporte, los sucesos, las entrevistas a madrileños famosos, etc., dejando de lado las noticias de ámbito nacional y mundial. La portada, como vemos en la imagen, contiene, por tanto, fotografías y vídeos de actualidad. Además, nos muestra enlaces a los distintos artículos de opinión, las noticias más leídas y a bitácoras (blogs) alojadas en el diario.

Cabe destacar que en la web del diario se nos ofrecen multitud de servicios adicionales, como información de transportes públicos, climatológica, guía telefónica, de tráfico o los niveles de polen, entre otros.

Este diario hace uso de las nuevas tecnologías que ofrece la web 2.0 como el uso de las Redes sociales Facebook y Twitter, la existencia de su propio canal en Youtube y las charlas interactivas (chats) con personajes de actualidad. Sin embargo, si acudimos a las Redes sociales, vemos que no tienen casi actividad por lo tanto, no representan aún una gran utilidad al menos hasta que se logre profundizar en cuál puede ser su impacto en el interés del público. 


\section{CONCLUSIONES: MALOS AUGURIOS Y FALTA DE MADURACIÓN EN EL PERIODISMO LOCAL EN LÍNEA}

Haciendo un cómputo de todo lo analizado hasta el momento y tras nuestra reflexión, podemos concluir que no sólo no se está llevando a cabo el "novedoso" periodismo local 2.0 (que definíamos al principio de esta comunicación) sobre un calco al tradicional si no que en muchos casos, el periodismo en línea está planteando llegar al público cercano mediante una labor poco tradicional con información sensacionalista o elaborada con exceso de premura, mezclando opinión e interpretación en muchos de los casos. Sin duda cabe destacar la falta de línea editorial, en general, y falta de coherencia en los contenidos.

Entre las cabeceras que hemos analizado encontramos una gran cantidad de 'Confidenciales'. Por motivos de espacio no haremos en este artículo una profusa relación de los existentes, baste decir que revisten la opinión de información y que se nutren de rumores y globos-sondas con el fin de conseguir audiencia y hacerse eco en otros periódicos de mayor envergadura.

Bien es cierto que en estos momentos de crisis, una de las causas que podríamos destacar para tal planteamiento informativo es la falta de inversión en personal y en medios, lo que hace que la información se empobrezca, pese a que no se precise de gran inversión.

La causa de la escasez de medios que aseguren calidad se puede basar en la falta de valentía de las compañías publicitarias para la inversión en medios digitales. Esto hace que la publicidad de los medios locales se circunscriba normalmente al apoyo de las Administraciones a través de la contratación de banderolas -banners- (como hemos visto en el análisis de Madridiario)

Por tanto, la búsqueda de la financiación, bien a través de la consolidación de la publicidad, bien mediante el cobro por acceso a artículos, es el gran reto de los editores, pero también, la definición del tipo de periodismo que quieren desarrollar.

El último fleco que queda por hilar en el futuro cercano con las tendencias tecnológicas y de consumo actuales, es que lo 2.0 todavía está lejos de estar consolidado en los medios locales. Si bien para los medios nacionales funciona bastante bien (bitácoras, foros de opinión, Redes sociales, comunidades sociales...) para los medios locales aún no se han sentado unas bases de segmentación popular lo suficientemente sólidas para animar la participación de los ciudadanos de los medios virtuales locales que les rodean. Lo que Vigotsky llamara Zona de Desarrollo Próximo del individuo, aplicado a la prensa en nuestra lectura.

\section{BIBLIOGRAFÍA}

AlADRo Vico, Eva (2011): "La Teoría de la Información ante las nuevas tecnologías de la comunicación" en Revista CiC Cuadernos de Información y Comunicación. Vol. 16. Disponible en: http://revistas.ucm.es/index.php/CIYC/article/view/36988/35797 Albornoz EsPiÑEIRA, Luis Alfonso (2004): Los diarios en línea de información general. El caso de los grandes periódicos en español. Tesis Doctoral dirigida por el Dr. 
Enrique Bustamante Ramírez. Facultad de Ciencias de la Información, Universidad Complutense de Madrid.

Armentia, José Ignacio; Caminos Marcet, José Ignacio; EleXgaray Arias, Jon; Marín Murillo, Flora \& Merchán Mota, Iker (2000): El diario digital. Análisis de los contenidos textuales, aspectos formales y publicitarios. Barcelona: Bosch.

Caldevilla Domínguez, David (2008): "El nuevo modelo de comunicación a partir de las Redes sociales y las TT.II.CC." en Revista de comunicación de la SEECI, n 16. Disponible en: www.ucm.es/info/seeci/Numeros/Numero 16/InicioN16.html

Díaz Noci, Javier \& Salaverría Aliaga, Ramón (Coords.) (2003): Manual de Redacción Cíber-periodística. Barcelona: Ariel.

EDO, Concepción (2002): "Las incertidumbres del periodismo en Internet" en Sala de prensa, $\mathrm{n}^{\circ}$ 44. Disponible en: www.saladeprensa.org/art369.htm.

EstéveZ, Jaime (2003): Periodismo en la Red. Madrid: Anaya Multimedia.

Gómez Calderón, Bernardo \& Paniagua Rojano, Francisco Javier (2005): "Las ediciones digitales de los diarios españoles. Nacimiento y consolidación de un sector en auge" en Razón y palabra, $\mathrm{n}^{\circ}$ 47. Disponible en: www.razonypalabra.org.mx/anteriores/n47/gomezpaniagua.html

GonZÁlez EsteBAN, José Luis (2009): "Modelos de periodismo local y estrategias ante la crisis: el caso del News \& Observer" en Revista Latina de Comunicación Social, $\mathrm{n}^{\mathrm{o}}$ 64. Disponible en:

www.ull.es/publicaciones/latina/09/art/14 813 11_MH/JL_Gonzalez Esteban.html

LaGunA, Antonio (1994): "Las secciones de lo local en los me $\overline{\bar{d}}$ ios de comunicación" en Actas de las Jornadas de Comunicación Local en la Comunidad Valenciana, Publicaciones FVMP.

MARTínez JuAn, Alicia (2003): "Los retos del periodismo local en la red: hacia una definición del espacio local en la Era global" en Sala de Prensa $\mathrm{n}^{\circ}$ 59. Disponible en: www.saladeprensa.org/art483.htm

MASIP MASIP, Pere (2008): El cíber-periodismo en Catalunya: apuntes sobre el estado de la cuestión en LÓPEZ GARCíA, Guillermo (Ed.) Comunicación local y nuevos formatos periodísticos en Internet: ciber-medios, confidenciales y weblogs. Disponible en: www.cibermediosvalencianos.es/ComunicacionLocal.pdf

SalaVerrría Aliaga, Ramón \& SÁdABA, Charo (eds.) (2004): Towards new media paradigms. II International Conference of COST A20. Pamplona: Eunate.

SAlaVERrRía AliagA, Ramón (2007): "La investigación sobre cíber-periodismo en España: tendencias, resultados y perspectivas" en Actas de la Jornada "La convergencia digital en los medios de comunicación valencianos". Valencia: Departament de Teoría dels Llenguatges i Ciències de la Comunicació, Universitat de València. Disponible en: www.cibermediosvalencianos.es/comloc/Salaverria.pdf

SalaVerrría Aliaga, Ramón (2008). "Cíber-periodismo: diez años de prensa digital en España” en FERnÁndez SAnz, Juan José (ed.). Prensa especializada actual. Doce calas. Madrid: McGraw-Hill, pp. 355-383.

SPARKS, Colin (2002): "La influencia de Internet en los medios de comunicación convencionales" en VidAl-Beneyto, José (Coord.) La Ventana Global: ciberespacio, esfera pública mundial y universo mediático. Madrid. Taurus.

VAQUERIZO GARCíA, María Belén (2012): "Enseñanza-aprendizaje con Web 2.0 y 3.0" en Revista de Comunicación Vivat Academia, $\mathrm{n}^{\mathrm{o}}$ especial de febrero de 2012. Disponible en: www.seeci.net/vivataca/numeros/n117E/PDFs/MBVaqu.pdf 
VARELA, Juan (2003): "Los diarios locales buscan un futuro digital” en www.soitu.es el 18 de marzo.

VV.AA. (2002): Especial Periodismo Digital de la Revista Sala de Prensa. Disponible en: www.saladeprensa.org Noviembre, Año IV, Vol.2.

\title{
www.madridiario.es
}

www.ojd.es/

www.alexa.com/

www.madrid.org/

\section{NIHIL OBSTAT. IMPRIMÁTUR}

\section{RESUMEN}

El periodismo ha evolucionado vertiginosamente en el epílogo del siglo pasado y en los prolegómenos del que recién hemos comenzado. El acceso casi instantáneo a la información, la proliferación de fuentes, la rapidez de comunicación y la externalización del uso de Internet fuera del ámbito meramente académico o profesional, propio del entorno laboral, ha abierto nuevas ventanas para esta 'vieja' profesión que poco a poco van siendo asimiladas por periodistas y lectores.

Palabras clave: periodismo, web 2.0, crisis profesional, fuentes informativas, Internet.

\begin{abstract}
Journalism has evolved dramatically in the epilogue of the last century and on the verge of a new era that we have just begun. The almost instant access to information, the proliferation of sources, rapid communication and Internet's use outside the purely academic or professional work environment, has opened new windows for this 'old' profession that are progresively assimilated by journalists and readers.
\end{abstract}

Keywords: journalism, web 2.0, profesional crisis, information sources, Internet.

\section{RÉSUMÉ}

Le journalisme a évolué de façon spectaculaire dans l'épilogue du dernier siècle et à la veille de ce que nous venons de commencer. L'accès presque instantané à l'information, la multiplication des sources, une communication rapide et l'externalisation utilisation d'Internet en dehors du milieu de travail purement académique ou professionnel même, a ouvert de nouvelles fenêtres pour cette «vieille» profession que peu à peu sont assimilés par les journalistes et les lecteurs.

Mots clé: journalisme, web 2.0, crise professionnelle, sources d'information, Internet. 